\title{
AFM in mode Peak Force applied to the study of un-worn Contact Lenses
}

\author{
J Torrent-Burgués ${ }^{1,2, *}$, F Sanz ${ }^{2,3}$
}

${ }^{1}$ Universitat Politècnica de Catalunya, Dpt. Enginyería Química, 08222 Terrassa

(Barcelona) Spain

${ }^{2}$ CIBER-BBN, Campus Rio Ebro-Edificio I+D, 50018 Zaragoza, Spain

${ }^{3}$ Universitat de Barcelona, Dpt. Química-Física, 08028 Barcelona, Spain

*Corresponding author. E-mail: juan.torrent@upc.edu. TIf: +34937398043, Fax: $+34937398225$

\section{Abstract}

Contact lenses (CLS) are of common use and the biocompatibility, topography and mechanical properties of the used materials are of major importance. The objective of this contribution is to apply the AFM in mode Peak Force to obtain surface topography and mechanical characteristics of un-worn CLs of different materials. One material of hydrogel, two of siloxane-hydrogel and one of rigid gas permeable, were used in the study. The results obtained with the different materials have been compared, at a nanoscopic level, and the conclusions are diverse. There is no significant influence of the two environments used to measure the characteristics of the CLs, either water or saline solution. The pHEMA hydrogel CL (Polymacon of Soflens) shows the highest values of roughness, adhesion and elastic modulus. The Siloxane-hydrogel $C L$ named Asmofilcon A of PremiO, presents the lowest values of mean roughness $\left(R_{a}\right)$, rootmean-square roughness (RMS or $\left.R_{q}\right)$, adhesion (Adh) and elastic modulus $\left(Y_{m}\right)$, meanwhile the siloxane-hydrogel $\mathrm{CL}$ named Lotrafilcon $\mathrm{B}$ of Air Optix presents the lowest value of skewness $\left(R_{\text {sk }}\right)$ and the rigid gas permeable $C L$, named RXD, presents the lowest values of kurtosis $\left(R_{k u}\right)$ and maximum roughness $\left(R_{\max }\right)$. 


\section{Keywords}

Peak Force mode, Contact lenses, Elastic modulus, Adhesion, Roughness

\section{Highlights}

The Peak Force mode of AFM provides surface topography as well as nanomechanical properties.

The hydrogel contact lens shows the highest values of surface roughness.

The hydrogel contact lens shows the highest values of adhesion and elastic modulus.

There is no significant influence of the environment, water or saline solution, on the measured properties.

\section{Introduction}

Contact lenses (CLS) are today of common use for visual defect corrections. CLs, in contrast to spectacles, are in contact with the eye and consequently the biocompatible properties of the used materials and their topographic and mechanical characteristics are of major importance in order to full fit the ocular tissues requirements, and do not provoke injuries during the wear. Manufacturers of CLs look for materials with low values of the elastic modulus, as well as a good level of wettability. Topographic and more specifically mechanical properties at a nanometric level have been considered only in a limited number of papers. The Atomic Force Microscopy (AFM) is a technique that becomes useful to determine these properties, as was pointed out in an earlier work by Rabke et al. [1]. Consequently, several authors [2-15] performed studies on CLs and using the AFM technique, but none of them used the Peak Force Quantitative Nanomechanics mode to determine the nanomechanical properties, such as the adhesion or the Young modulus, also named elastic modulus.

Grobe et al. [2] studied the surface chemistry and topography of Etafilcon-A hydrogel CLs as a function of polymer processing, by using AFM, and concluded that the processing technique has influence in both the surface chemistry (surface composition, wettability) and the topography. Maldonado et al. [8] examined the impact of manufacturing and material composition on the surface topographic characteristics 
of five types of hydrogel CLs. Observations were made using both Scanning Electron Microscopy (SEM) and AFM, indicating that cast-molded lenses show lower root-meansquare (RMS) roughness values, in agreement with the results of Rabke et al. [1] and Grobe et al. [2]. Kim et al. [4, 5] investigated the surface of hydrogel pHEMA-based CLs by using AFM and measuring the friction and adhesive forces. They found that in saline solution these magnitudes were significantly reduced, compared to those measured for the surface-dehydrated state. Opdahl et al. [6] and Koffas et al. [7] investigated the surface mechanical properties of pHEMA-based hydrogel CLs as a function of ambient relative humidity and bulk water content by using AFM force curves. They found a balance in between the dehydration and hydration rates at around $50-60 \%$ relative humidity.

From the development of the new siloxane-hydrogel $(\mathrm{Si}-\mathrm{H})$ materials, studies were made also on this type of CLs. Gonzalez-Meijome et al. [10] studied several Si-H materials, shown in Table 1, and concluded that Balafilcon A presents a more irregular surface, probably due to the plasma oxidation treatment used to improve wettability, having Galyfilcon A and Lotrafilcon A the smother surface. Lira et al. [13] studied three different Si-H materials (see Table 1) and also observed that Galyfilcon has the smother surface meanwhile Balafilcon A has the more irregular one. Guryca et al. [12] studied several $\mathrm{Si}-\mathrm{H}$ and hydrogel materials and obtained that the surface roughness depends on the technique used to fabricate the CLs. They observed that the lathecutting technique provides more roughness meanwhile both the spin-coating (as hidrogel Filcon $1 \mathrm{~A}$ from Wilens) and cast-mulding (as Si-H Galyfilcon A) techniques provide less roughness. Giraldez et al. [14] also studied several Hydrogel and Si-H materials and observed that the flattest surface corresponds to both hydrogel Omafilcon A and Si-H Comfilcon A, among those studied. Looking Table 1 it can be seen that the roughness shown by the CLs depends more on the manufacturer, the method of manufacture, or the surface treatment, than on the material, since some hydrogel CLs are less rough than other Si-H CLs, and on the contrary. Also, different authors report different values for the same material. Finally, Zhou et al. [15] proposed to measure the frictional properties of CLs since them could have a great impact on their clinical performance.

The mean goal of the paper is to obtain the adhesion and the Young's modulus of different CL materials in different aqueous media, water and saline solution, using the Peak Force mode, and to compare the values. The Peak Force mode is a recent development in AFM that permits to obtain nanomechanical properties, as Young modulus and adhesion, at the same time that a topographic image of the surface sample is registered. The Peak Force mode covers a wide range of Young modulus 
values, between $1 \mathrm{Mpa}$ and $50 \mathrm{GPa}$, and adhesion values, between $10 \mathrm{pN}$ and $10 \mu \mathrm{N}$. The Peak Force mode operates in intermittent contact mode controlling the maximum applied force and performing force curves in each contact point. More details on the AFM technique can be found in references $[16,17]$ and on the Peak Force mode in references $[18,19]$. For one of the selected materials $(\mathrm{Si}-\mathrm{H})$ there is no references in literature concerning to the adhesion and elastic modulus at a nanometric level. The treatment of the obtained data provides also topographic images and statistical values of mean roughness $\left(R_{a}\right)$, root-mean-square roughness (RMS or $\left.R_{q}\right)$, kurtosis $\left(R_{k u}\right)$ and skewnwss $\left(R_{s k}\right)$, and for one of the CLs, named PremiO, there was neither a reported topographic analysis in literature. Finally, the work provides these values for different materials of CLs using the same technique and procedure, which affords a higher level of confidence in comparing them.

Table 1. Topographic values for different hydrogel $(\mathrm{H})$ and siloxane-hydrogel ( $\mathrm{Si}-\mathrm{H}$ ) contact lenses, reported by different authors. $\mathrm{R}_{\mathrm{a}}$ : mean roughness, $\mathrm{R}_{\mathrm{q}}$ : root-mean-square roughness.

\begin{tabular}{|c|c|c|c|c|}
\hline Name & $\begin{array}{ll}\text { Material } & \& \\
\text { Manufacturer } & \end{array}$ & $\mathrm{R}_{\mathrm{a}}(\mathrm{nm})$ & $\mathrm{R}_{\mathrm{q}}(\mathrm{nm})$ & Reference \\
\hline Lotrafilcon A & Si-H Ciba Vision & $\begin{array}{l}3.6 \\
7.3\end{array}$ & $\begin{array}{l}4.67 \\
9.8\end{array}$ & $\begin{array}{l}{[10]} \\
{[12]}\end{array}$ \\
\hline Balafilcon A & Si-H Bausch \& Lomb & $\begin{array}{l}9.55 \\
4.8 \\
7.04\end{array}$ & $\begin{array}{l}12.26 \\
6.6 \\
9.5\end{array}$ & $\begin{array}{l}{[10]} \\
{[12]} \\
{[13]}\end{array}$ \\
\hline Galyfilcon A & $\begin{array}{l}\text { Si-H } \\
\text { Johnson\&Johnson }\end{array}$ & $\begin{array}{l}5.39 \\
0.7 \\
2.32\end{array}$ & $\begin{array}{l}6.75 \\
0.8 \\
3.04\end{array}$ & $\begin{array}{l}{[10]} \\
{[12]} \\
{[13]}\end{array}$ \\
\hline Etafilcon A & H Johnson\&Johnson & 3.2 & 3.9 & [12] \\
\hline Nefilcon A & H Ciba Vision & $\begin{array}{l}4.8 \\
11.25\end{array}$ & $\begin{array}{l}2.9 \\
15.41\end{array}$ & $\begin{array}{l}{[12]} \\
{[14]}\end{array}$ \\
\hline Vasurfilcon & H Ciba Vision & 2.0 & 2.6 & [12] \\
\hline Filcon 1A & $\begin{array}{l}\text { H Wilens } \\
\text { H Wichterle \& Vacik }\end{array}$ & $\begin{array}{l}0.9-2.0 \\
16.8\end{array}$ & $\begin{array}{l}1.2-2.8 \\
26.4\end{array}$ & [12] \\
\hline Filcon 4A & H Ciba Vision & 18.8 & 24.1 & [12] \\
\hline Lotrafilcon B & Si-H Ciba Vision & $\begin{array}{l}5.1 \\
4.5\end{array}$ & $\begin{array}{l}7.3 \\
5.7\end{array}$ & $\begin{array}{l}{[12]} \\
{[13]}\end{array}$ \\
\hline Omafilcon & H Cooper Vision & 1.9 & 2.78 & [14] \\
\hline Hioxifilcon & H MarkEnnovy & 4.31 & 5.5 & [14] \\
\hline Ocufilcon B & H Cooper Vision & 11.01 & 14.38 & [14] \\
\hline Senofilcon A & $\begin{array}{l}\text { Si-H } \\
\text { Johnson\&Johnson }\end{array}$ & 3.33 & 4.06 & [14] \\
\hline Comfilcon A & Si-H Cooper Vision & 1.56 & 2.34 & [14] \\
\hline
\end{tabular}




\section{Materials and methods}

Soft CLs of two different siloxane-hydrogel ( $\mathrm{Si}-\mathrm{H})$ materials, commercialized as PremiO (P), from Menicon, and Air Optix (AO), from CIBA Vision, one soft CL of pHEMA hydrogel $(\mathrm{H})$ material (Soflens, from Bausch \& Lomb) and one rigid gas permeable CL of silicone-based material, RGP (RXD, from Boston), were used. The technical names and characteristics of the materials are shown in Table 2.

Table 2. Characteristics of the different contact lenses used in the study provided by manufacturers. Dk: oxygen permeability.

\begin{tabular}{|l|l|l|l|l|}
\hline & PremiO & Air Optix & Soflens & RXD \\
\hline Name & Asmofilcon A & Lotrafilcon B & Polymacon & $\begin{array}{l}\text { Itabisfluorofocon } \\
\text { A }\end{array}$ \\
\hline FDA Group & I & I & I & - \\
\hline \% water & 40 & 33 & 38 & - \\
\hline Surface treatment & Nanogloss & $\begin{array}{l}\text { PM } \\
\text { polymerization }\end{array}$ & - & - \\
\hline Contact angle & 27 & 78 & 17 & 39 \\
\hline $\begin{array}{l}\text { Dk·10 } \\
\left(\mathrm{cm}^{2} / \mathrm{s}\right) \cdot(\mathrm{mlO} / \mathrm{ml} \cdot \mathrm{mmHg})\end{array}$ & 129 & 110 & 8.4 & 24 \\
\hline Young modulus $(\mathrm{MPa})$ & 0.9 & 1.2 & 0.44 & $\approx 5$ \\
\hline
\end{tabular}

\subsection{Samples preparation}

The samples were prepared taking the CLs from the blister, washing gently with water, cutting a small piece of the central part $\left(1 \times 1 \mathrm{~mm}^{2}\right)$, fixing with glue on a clean Teflon support mounted on a magnetic plate, and immersing either in saline solution or water. Prepared samples were left 30 min before imaging so as to ensure hydration equilibrium. Finally, the sample was mounted in a cell for liquid systems to perform the AFM experiment. In the case of RGP lenses, which are provided in a wetting solution, it is important to remove the wetting layer in order to obtain good AFM images and mechanical values. 


\subsection{Techniques and equipment}

AFM in Peak Force Quantitative Nanomechanics mode was done, using a Multimode 8 and Nanoscope $V$ electronics (Bruker). The study was carried out in liquid media using silicon nitride triangular cantilevers with pyramid tips of silicon oxide of low spring constant ( $0.35 \mathrm{nN} / \mathrm{nm}$ nominal). The resonant frequency in liquid was of $2 \mathrm{kHz}$ and the peak force amplitude of $300 \mathrm{~nm}$. A maximum vertical force between $0.5-3 \mathrm{nN}$ was applied depending on the Young modulus of the sample (a sample deformation over $3 \mathrm{~nm}$ is required). The selected piezo-scanner was for scanning small areas. The scanned area of the images here presented is $5 \times 5 \mu \mathrm{m}^{2}$ and the analyzed parameters refer to this area (it is important to specify this information since the obtained values of the parameters depend in some degree on the size of the scanned area). The room was maintained at controlled ambient temperature $\left(20^{\circ} \mathrm{C}\right)$ and humidity $(50 \%)$. Image treatment was done with the software Nanoscope Analysis v1.2.

The equipment was calibrated prior to the sample measurements with the thermal noise method and using a mica surface. This calibration allows us to obtain a precise spring constant and consequently quantitative values of the Young modulus.

For the topographic analysis, five parameters have been used: mean roughness $\left(R_{a}\right)$, root-mean-square roughness (RMS or $\left.R_{q}\right)$, skewnes $\left(R_{s k}\right)$, kurtosis $\left(R_{k u}\right)$, and maximum roughness $\left(R_{\max }\right)$, which are defined as follows, on the basis of powers of the deviations $Z_{j}$ of the heights in respect to the mean value:

- Mean roughness $\left(\mathrm{R}_{\mathrm{a}}\right)$

Arithmetic average of the absolute values of the surface height deviations measured from the mean plane $\left(\mathrm{Z}_{\mathrm{j}}\right) . \mathrm{N}$ is the number of values.

$$
R_{a}=\frac{1}{N} \sum_{j=1}^{N}\left|Z_{j}\right|
$$

- Root-mean-square roughness (RMS or $\mathrm{R}_{\mathrm{q}}$ )

Standard deviation of the $Z$ values.

$$
R_{q}=\sqrt{\frac{\sum\left(Z_{i}\right)^{2}}{N}}
$$

- $\quad$ Skewness $\left(R_{\mathrm{sk}}\right)$

Skewness is a non-dimensional quantity that measures the symmetry of surface data about a mean data profile. Values of $R_{s k}=0$ suggest a uniform distribution of heights in respect to the mean value, meanwhile values of $R_{s k} \neq 0$ suggest an 
asymmetric distribution. For $R_{s k}>0$ there are preponderance of peaks and for $R_{s k}<0$ there are preponderance of valleys.

$$
R_{s k}=\frac{1}{R_{q}{ }^{3}} \frac{1}{N} \sum_{j=1}^{N} Z_{j}^{3}
$$

- $\quad$ Kurtosis $\left(R_{k u}\right)$

Kurtosis is a non-dimensional quantity that evaluates the shape of distributions around the mean value. A value of $R_{k u}=3$ indicates a uniform distribution, for $R_{k u}<3 a$ flatly distribution and for $R_{k u}>3$ a sharply distribution in respect to the mean.

$$
R_{k u}=\frac{1}{R_{q}{ }^{4}} \frac{1}{N} \sum_{j=1}^{N} Z_{j}^{4}
$$

- Maximum roughness $\left(R_{\max }\right)$

Maximum distance from peak to valley.

- Young modulus ( $\left.\mathrm{Y}_{\mathrm{m}}\right)$

The Young modulus, or elastic modulus, measures the response, the deformation, of a material when a force per unit area is applied. Units are in Pa, MPa or GPa. With the AFM technique quantitative measurements of the surface elastic modulus can be obtained. From the force curves obtained with the Peak Force mode, the shape and slope of the curve zone were contact tip-sample exist provide information on the surface elasticity.

- $\quad$ Adhesion (Adh)

Adhesion, or adhesion force, is a measure of the binding interaction between two material surfaces as a result of intermolecular forces. In the Peak Force mode the information about adhesion is obtained just when the tip lifts the sample and returns to its initial position. This corresponds in the force curve as the distance between the base line and the minimum point in the curve. 


\section{Results and discussion}

Figure 1 shows topographic AFM images of the surface for the different CLs. It is worth to comment that the PremiO CL have difficulties with the cantilever engage in the Peak Force mode, probably due to the surface treatment that the lenses wear. Figure 2 shows one section profile for each of the AFM images of Figure 1. Figure 3 and Figure 4 present maps of Young modulus and adhesion, respectively, for the analyzed CLs and obtained point to point from the force curves in the scanned area.

Observing the topographic images, it is seen that the $\mathrm{HCL}$ presents more holes in the surface than the others CLs, meanwhile the RGP CL presents more lines, probably due to the manufacturing process. Section profiles in Figure 2 show this fact, and it can be also seen that the depth of the holes for the $\mathrm{HCL}$ is greater than that of the lines for the RPG CL. The section profile of the P CL seems to indicate that it has the more regular surface. Images of Figure 3 are all at the same scale of Young modulus value (color scale), and thus it can be seen that, semi-quantitatively, the H CL presents the highest value of Young modulus meanwhile the P CL presents the lowest one. Images of Figure 4 are all at the same scale of adhesion value (color scale), and thus it can be seen that, semi-quantitatively, the H CL presents the highest value of adhesion.

The Peak Force mode performs and registers force curves at several points in the scanned area, and the application of the Software Nanoscope Analysis permits to obtain a mean value of $Y_{m}$ and Adh for the scanned area. Topographical values are also obtained for the scanned area. For each material 2 CLs were used, and for each CL 3 zones were scanned, obtaining a set of values. With the obtained data and using a standard statistical program, the mean values and standard deviations of the different parameters for each material were obtained and reported in Table 3. Two sets of measurements were made, one in water and another in saline solution. Table $3 \mathrm{a}$ shows the results obtained in both of the studied sets. The statistical analysis of the results shows no significant differences between the values obtained in both sets of measurements, so no significant influence of the environment seems to be noticeable ( $P$ value $>0.05$ ): $P=0.116$ for $H C L, P=0.375$ for $A O C L, P=0.375$ for $P C L, P=0.236$ for RGP CL. Thus, Table $3 b$ shows the mean values for each $C L$ without discriminating the environment. 


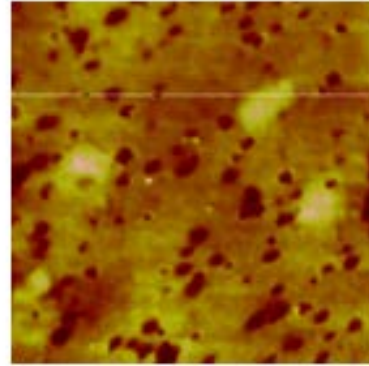

$\mathrm{H}$

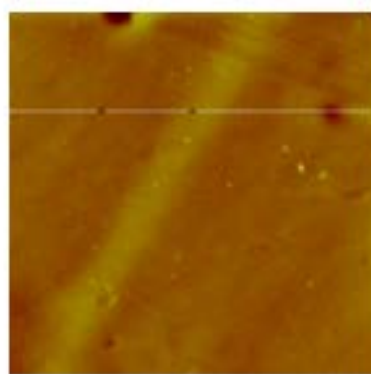

$\mathrm{AO}$

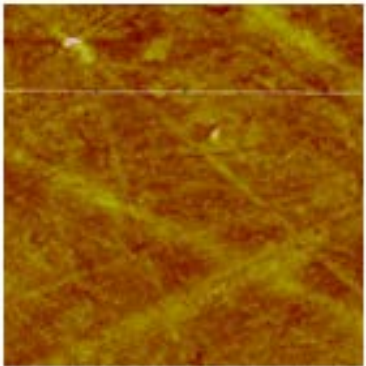

RGP

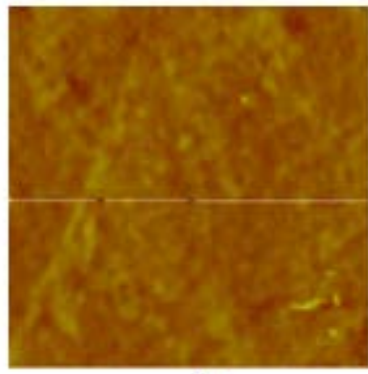

$P$

Figure 1. Topographic images of the surface of the different unworn CLs: PremiO (P), Air Optix (AO), Hydrogel (H) and Rigid Gas Permeable (RGP). Scanned area: $5 \times 5 \mu \mathrm{m}^{2}$.

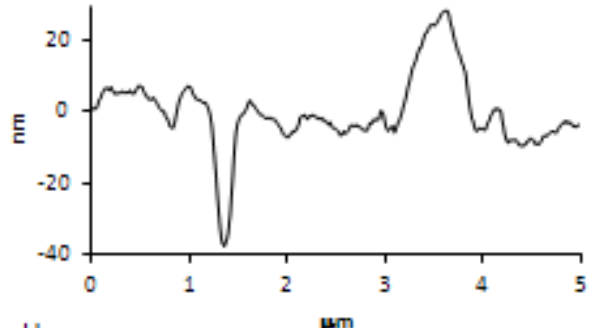

$\mathrm{H}$

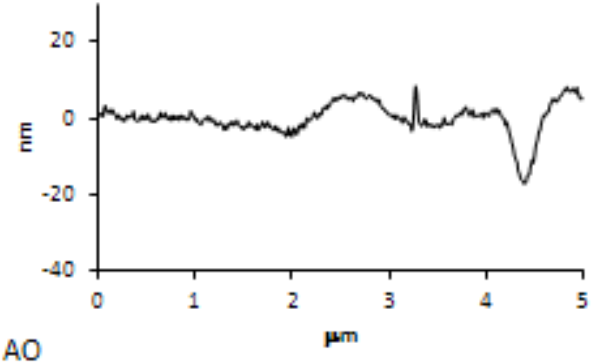

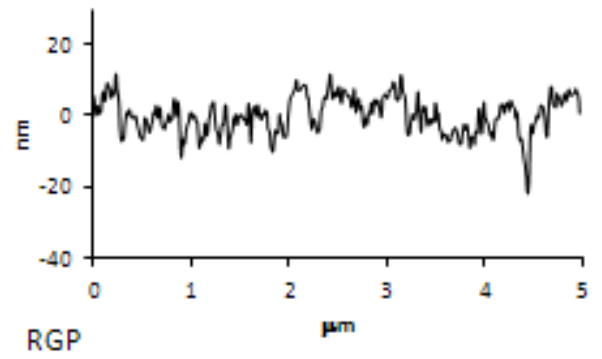

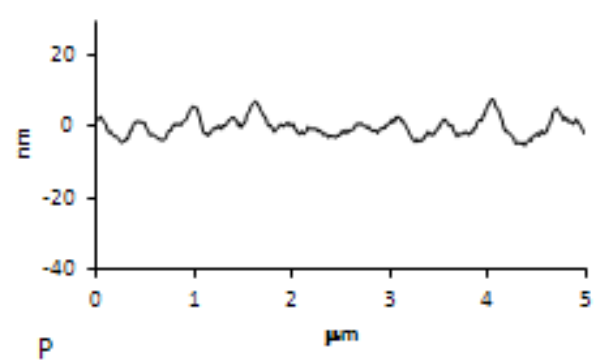

Figure 2. Profile sections for images in Figure1. 


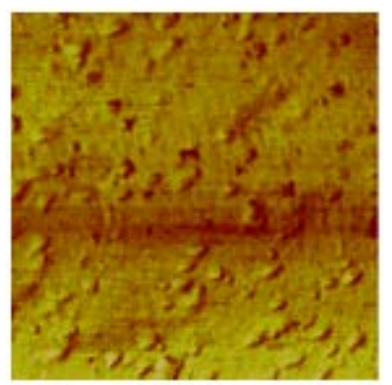

$\mathrm{H}$

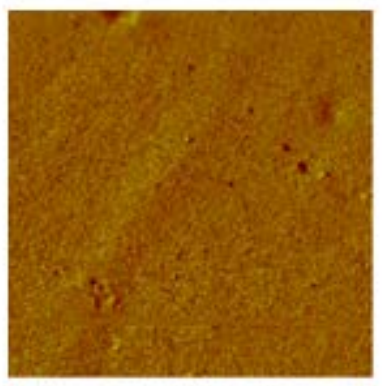

$\mathrm{AO}$

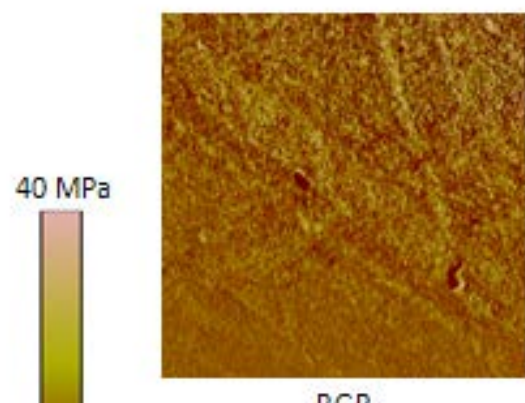

RGP

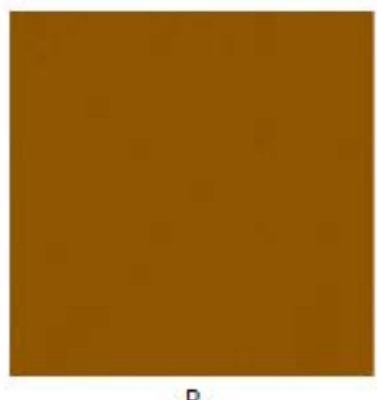

Figure 3. Young modulus map for the four materials of CLs indicated in Figure 1. Scanned area $5 \times 5 \mu \mathrm{m}^{2}$.

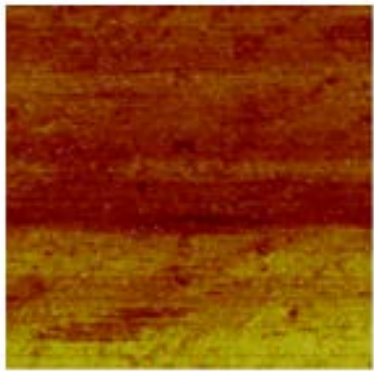

$\mathrm{H}$

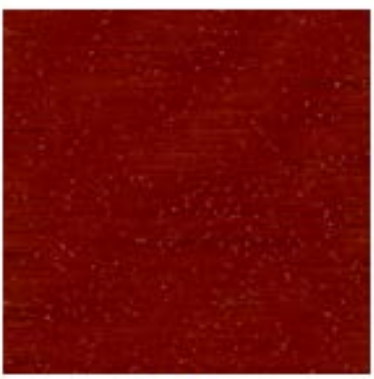

$\mathrm{AO}$

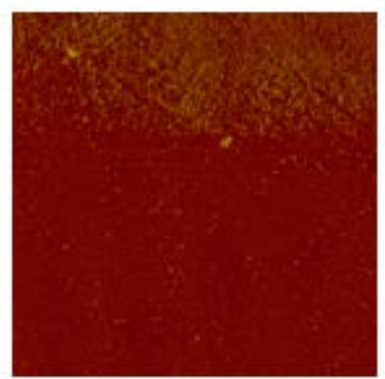

RGP

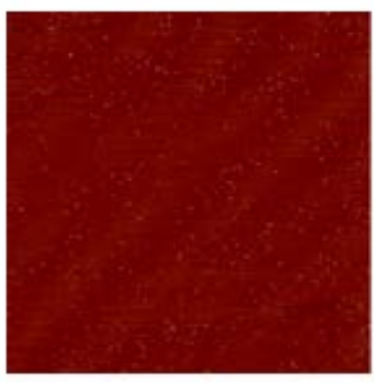

P

Figure 4. Adhesion map for the four materials of CLs indicated in Figure 1. Scanned area 5x5 $\mu \mathrm{m}^{2}$. 
Table 3. Mean values and standard deviations (in parenthesis) obtained from the topographic and nanomechanical analysis. a) Considering the environment, b) non-considering the environment (all data together). $\mathrm{H}=$ hydrogel Soflens, $\mathrm{AO}=$ siloxane-hydrogel Air Optix, $\mathrm{P}=$ siloxane-hydrogel PremiO, RGP=rigid gas permeable RXD.

a

\begin{tabular}{|l|l|l|l|l|l|l|l|}
\hline & $\begin{array}{l}\mathrm{R}_{\mathrm{a}} \\
(\mathrm{nm})\end{array}$ & $\mathrm{R}_{\mathrm{q}}(\mathrm{nm})$ & $\mathrm{R}_{\mathrm{sk}}$ & $\mathrm{R}_{\mathrm{ku}}$ & $\begin{array}{l}\mathrm{R}_{\max } \\
(\mathrm{nm})\end{array}$ & $\begin{array}{l}\text { Adh } \\
(\mathrm{nN})\end{array}$ & $\begin{array}{l}\mathrm{Y}_{\mathrm{m}} \\
(\mathrm{MPa})\end{array}$ \\
\hline H water & 8.3 & 12.0 & 0.9 & 20.3 & 166.0 & 1.03 & 22 \\
& $(1.7)$ & $(1.4)$ & $(2.2)$ & $(26.4)$ & $(74.5)$ & $(0.40)$ & \\
\hline H saline & 8.3 & 13.4 & 2.0 & 24.0 & 185.3 & 0.10 & 36 \\
& $(1.0)$ & $(1.1)$ & $(2.4)$ & $(16.8)$ & $(60.6)$ & $(0.14)$ & \\
\hline AO water & 5.2 & 7.8 & -0.9 & 19.3 & 100.8 & 0.20 & 10.7 \\
& $(3.1)$ & $(5.5)$ & $(1.3)$ & $(18.8)$ & $(57.9)$ & $(0.14)$ & $(9.5)$ \\
\hline AO saline & 4.5 & 6.4 & 0.6 & 16.1 & 203 & 0.11 & 10.8 \\
& $(2.2)$ & $(4.7)$ & $(2.3)$ & $(16.5)$ & & $(0.13)$ & $(17.0)$ \\
\hline P water & 3.2 & 4.2 & 1.2 & 12.0 & 76.2 & 0.22 & 1.2 \\
& $(0.7)$ & $(0.9)$ & $(0.6)$ & $(9.4)$ & $(27.8)$ & $(0.25)$ & $(0.7)$ \\
\hline P saline & 4.1 & 5.03 & 0.65 & 7.5 & 129 & 0.02 & 3.0 \\
& $(0.9)$ & $(0.04)$ & $(0.50)$ & $(3.1)$ & & $(0.03)$ & $(4.7)$ \\
\hline RGP water & 6.3 & 8.0 & 0.7 & 8.1 & 89.4 & 0.45 & 5.1 \\
& $(3.2)$ & $(3.7)$ & $(0.6)$ & $(8.3)$ & $(21.3)$ & $(0.63)$ & $(4.8)$ \\
\hline RGP saline & 4.1 & 5.3 & -0.4 & 4.9 & 63.5 & 0 & $(0)$ \\
& $(1.0)$ & $(1.1)$ & $(1.1)$ & $(2.3)$ & $(4.5)$ & & $(4.9)$ \\
\hline
\end{tabular}

b

\begin{tabular}{|l|l|l|l|l|l|l|l|}
\hline & $\begin{array}{l}\mathrm{R}_{\mathrm{a}} \\
(\mathrm{nm})\end{array}$ & $\mathrm{R}_{\mathrm{q}}(\mathrm{nm})$ & $\mathrm{R}_{\mathrm{sk}}$ & $\mathrm{R}_{\mathrm{ku}}$ & $\begin{array}{l}\mathrm{R}_{\max } \\
(\mathrm{nm})\end{array}$ & Adh (nN) & $\begin{array}{l}\mathrm{Y}_{\mathrm{m}} \\
(\mathrm{MPa})\end{array}$ \\
\hline $\mathrm{H}$ & 8.3 & 12.7 & 1.4 & 22.1 & 175.7 & 0.66 & 29.0 \\
& $(1.3)$ & $(1.3)$ & $(2.2)$ & $(19.9)$ & $(61.6)$ & $(0.59)$ & $(9.9)$ \\
\hline $\mathrm{AO}$ & 4.9 & 7.3 & -0.2 & 18.0 & 126.3 & 0.14 & 10.7 \\
& $(2.4)$ & $(4.6)$ & $(1.9)$ & $(15.7)$ & $(69.6)$ & $(0.13)$ & $(12.3)$ \\
\hline $\mathrm{P}$ & 3.6 & 4.5 & 1.0 & 10.2 & 89.4 & 0.12 & 2.1 \\
& $(0.9)$ & $(0.8)$ & $(0.6)$ & $(7.2)$ & $(34.8)$ & $(0.18)$ & $(3.2)$ \\
\hline RGP & 5.2 & 6.7 & 0.1 & 6.5 & 76.4 & 0.22 & 6.1 \\
& $(2.4)$ & $(2.8)$ & $(1.0)$ & $(5.7)$ & $(19.8)$ & $(0.45)$ & $(4.7)$ \\
\hline
\end{tabular}


Experimental results show that the studied hydrogel $\mathrm{CL}(\mathrm{H})$ presents the highest values of $R_{a}, R_{q}, R_{\max }, R_{s k}, R_{k u}$, Adh and $Y_{m}$. The PremiO Si-H CL (P) presents the lowest values of $R_{a}, R_{q}$, Adh and $Y_{m}$, meanwhile the Air Optix Si-H CL (AO) presents the lowest value of $R_{s k}$ and the RXD RGP CL (RGP) presents the lowest values of $R_{k u}$ and $R_{\max }$. The observed tendencies are given in Table 4 . It is also seen in Table 3 that the P Si-H CL shows more reproducible values (less standard deviation) of both $\mathrm{R}_{\mathrm{a}}$ and $\mathrm{R}_{\mathrm{q}}$ parameters, which can be indicative of a more homogeneous surface at the nanoscopic level. In reference to the analyzed parameters, $R_{k u}$ and $R_{\max }$ present the highest standard deviations in all samples.

Table 4. Observed tendencies for the analyzed CLs parameters.

\begin{tabular}{|l|l|}
\hline $\mathrm{R}_{\mathrm{a}}$ & $\mathrm{H}>\mathrm{RGP}>\mathrm{AO}>\mathrm{P}$ \\
\hline $\mathrm{R}_{\mathrm{q}}$ & $\mathrm{H}>\mathrm{AO}>\mathrm{RGP}>\mathrm{P}$ \\
\hline $\mathrm{R}_{\mathrm{sk}}$ & $\mathrm{H}>\mathrm{P}>\mathrm{RGP}>\mathrm{AO}$ \\
\hline $\mathrm{R}_{\mathrm{ku}}$ & $\mathrm{H}>\mathrm{AO}>\mathrm{P}>\mathrm{RGP}$ \\
\hline $\mathrm{R}_{\max }$ & $\mathrm{H}>\mathrm{AO}>\mathrm{P}>\mathrm{RGP}$ \\
\hline Adh & $\mathrm{H}>\mathrm{RGP}>\mathrm{AO}>\mathrm{P}$ \\
\hline $\mathrm{Y}_{\mathrm{m}}$ & $\mathrm{H}>\mathrm{AO}>\mathrm{RGP}>\mathrm{P}$ \\
\hline
\end{tabular}

\subsection{Topographic analysis}

Dealing with the hydrogel CL type, the value we have obtained for $R_{q}$ is comparable with values reported in the literature. Rabke et al. [1] reported for Polymacon lenses values of $R_{q}$ ranging from 7 to $28 \mathrm{~nm}$, Grobe et al. [2] reported for Etafilcon-A lenses values of $R_{q}$ ranging from 5.0 to $25.2 \mathrm{~nm}$, and Maldonado et al. [8] reported values of $R_{q}$ ranging from 3.9 to $12.3 \mathrm{~nm}$, which depend in all of these studies on the fabrication method and on the face of the lenses. These studies clearly show that the fabrication technique has a notable influence on the lens roughness, being the cast-molded lenses those showing lower $R_{q}$ values. Kim et al. $[4,5]$ also reported values of $R_{q}$ in pHEMA-based hydrogel lenses ranging from 8 to $23 \mathrm{~nm}$.

Dealing with the RGP CL type, our value of roughness is also comparable with the value of $9 \mathrm{~nm}$ reported by Bruinsma et al. [9]. 
Dealing with the Si-H CL type, our values of $\mathrm{R}_{a}$ and $\mathrm{R}_{\mathrm{q}}(4.86$ and $7.26 \mathrm{~nm})$ for the AO CL (Table 3) made from Lotrafilcon B, are comparable with those of Lira et al. [13] (4.5 and $5.7 \mathrm{~nm}$ ) and very similar to those of Guryca et al. [12] (5.1 and $7.3 \mathrm{~nm}$ ) (see Table 1). No reported values for the P CL were found in literature. Nevertheless, Senofilcon A, of Acuvue Oasys from Johnson\&Johnson, is a Si-H material that shows a similar topography as Asmofilcon $\mathrm{A}$ of the $\mathrm{P} \mathrm{CL}$, and also some reported material properties are similar (38\% water content, $\mathrm{DK}=103, \mathrm{Y}_{\mathrm{m}}=0.72 \mathrm{MPa}$ ). Thus, comparing our values of $R_{a}$ and $R_{q}$ (3.65 and $4.52 \mathrm{~nm}$ ) for the $P C L$ (Table 3) with those of Senofilcon A (3.33 and $4.06 \mathrm{~nm}$ ) reported by Giraldez et al. [14](see Table 1), it is seen that are similar. Giraldez et al. [14] also gave values of $R_{s k}$ and $R_{k u}$ for Senofilcon $A$ $(0.74 \pm 0.41$ and $3.7 \pm 1.63)$, which are slightly lower than the values reported in Table 3

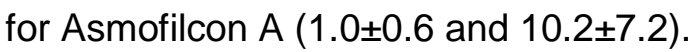

\subsection{Nanomechanical analysis}

Comparing our values of $Y_{m}$ with those reported by the different manufactures (see Table 2 and also reference [20]) measured with a different technique to AFM, it is observed that the values obtained by us using AFM are higher for all the studied CLS except the RGP CL, which show similar values. The difference between values is more notable for the hydrogel CL (29 MPa from AFM vs $0.44 \mathrm{MPa}$ from the manufacturer) and for the AO CL (10.7 MPa from AFM vs 1.2 MPa from the manufacturer). The differences can be attributed to the measuring technique, and for the hydrogel CL also to the factor of the surface hydration state that will be commented below. According to the Peak Force measurements, the hydrogel CL presents the highest value of $Y_{m}$, meanwhile the $\mathrm{P}$ Si-H CL presents the lowest one. Manufacturers search for materials with low values of $Y_{m}$. In table 2 the lowest value corresponds to hydrogel $C L$, being this result the opposite to that obtained in the present work using a technique that analyze the nanometric range of the surface, as AFM measurements only affect a nanometric thickness. The values of $Y_{m}$ reported by the different manufactures, and by some authors [21], were obtained using indentations at the macroscopic-microscopic level using big areas, of around $1 \mathrm{~mm} \times 1 \mathrm{~mm}$. So, values in Table 2 are not referred strictly to the surface layer as do the Peak Force mode of AFM. For that, the values obtained in both situations are different.

In respect to adhesion values, Kim et al. [4] reported values of adhesion of 1.4 $\mathrm{nN}$ for a hydrogel Polymacon lens and near null for a hydrogel Ocufilcon-D lens, in saline solution, meanwhile these values increase to $17-24 \mathrm{nN}$ in surface-dehydrated lenses. They also reported values of adhesion of $3.7 \mathrm{nN}$ for a pHEMA lens and near 
null value for a pHEMA-MA lens [5]. These values are in agreement with the values measured in the present study. In respect to Young modulus values, Kim et al. [5] reported values of $1.34 \mathrm{MPa}$ for a pHEMA lens and of $0.47 \mathrm{MPa}$ for a pHEMA-MA lens. These values are in more agreement with the bulk elastic modulus of these CLs reported by manufacturers [5] than those reported by us in the present study. Nevertheless, the global set of the reported values in literature show a wide dispersion.

In the case of soft CLs, made of hydrogel or siloxane-hydrogel, the hydration equilibrium of the surface can affect the adhesion values, which are higher in a surfacedehydrated lens [4]. The same could be expected for the Young modulus. Opdhal et al. [6] found values of surface elastic modulus for pHEMA bulk-hydrated lenses ranging from 25 to $45 \mathrm{MPa}$, depending on the relative humidity, versus the value of $0.3 \mathrm{MPa}$ for the bulk modulus of bulk-hydrated lens. These authors also reported values of surface elastic modulus higher than 70 MPa for bulk dehydrated lenses, versus the value of 1 Gpa for the bulk modulus of bulk-dehydrated lens. These values are higher than those of Kim et al. [5], and thus the authors point to the dehydration rate of the interface as a sufficient factor affecting the mechanical properties of the CL surface, even at high humidity.

Our values of Young modulus obtained after $30 \mathrm{~min}$ of preparation and immersion of the sample perhaps correspond to a non-well equilibrated hydration state of the surface lens. Consequently the Young modulus values obtained by us for the hydrogel lens with a similar technique as AFM are higher than those reported in the bibliography by Kim et al. [5] but similar to those reported by Opdahl et al. [6]. From the done experiments and the analysis of bibliography, the authors have seen the importance of the sample preparation and measurement conditions, and that the time for sample conditioning and humidity level in the microscope chamber can influence the measured values. This influence is even more pronounced since nanomechanical properties are measured at the surface level with the Peak Force mode of AFM. In consequence, the authors are planning a complete set of experiments in a near future to investigate these influences using the Peak Force mode.

\section{Conclusions}

The Peak Force mode of AFM is a useful technique providing topography and roughness parameters, such as mean roughness $\left(R_{a}\right)$, root-mean-square roughness $\left(R_{q}\right)$, kurtosis $\left(R_{k u}\right)$, skewnwss $\left(R_{s k}\right)$ and maximum roughness $\left(R_{\max }\right)$, as well as 
nanomechanical properties, such as adhesion (Adh) and Young modulus $\left(\mathrm{Y}_{\mathrm{m}}\right)$. For the four materials of CLs studied, hydrogel $(H)$, rigid gas permeable (RGP), siloxanehydrogel Air Optix (AO) and siloxane-hydrogel PremiO (P), the study has allowed to obtain tendencies in the values of those parameters, which are of importance for the biocompatibility of the CLs. This study encourages the authors to apply the Peak Force mode to the study of worn CLs, which will afford new information of clinical relevance on the changes provoked by the wear in the surface characteristics of the CLs.

\section{Acknowledgments}

The authors thank to C. Serés, MSc, for providing the contact lenses, and to G. Oncins, PhD, for the help in AFM utilization.

\section{References}

[1] C.E. Rabke, P.L. Valint, D.M. Ammon, International Contact Lens Clinic 22 (1995) 32.

[2] G.L. Grobe III, P.L. Valint, D.M. Ammon, J Biomed Mater Res 32 (1996) 45.

[3] S. Bhatia, E.P. Goldberg, J.B. Enns, The CLAO J 23 (1997) 264.

[4] S.H. Kim, C. Marmo, G.A. Somorjai, Biomater 22 (2001) 3285.

[5] S.H. Kim, A. Opdhal, C. Marmot, G.A. Somorjai, Biomater 23 (2002) 1657.

[6] A. Opdahl, S.H. Kim, T.S. Koffas, C. Marmo, G.A. Somorjai, J Biomed Mater Res A 67A (2003) 350.

[7] T.S. Koffas, A. Opdhal, C. Marmo, G.A. Somorjai, Langmuir 19 (2003) 3453.

[8] C. Maldonado-Codina, N. Efron, Clin Exp Optom 88 (2005) 396.

[9] G.M. Bruinsma, M. Rustema-Abbing, J. de Vries, H.J. Busscher, M.L. van der Linden, J.M.M. Hooymans, H.C. van der Mei, Biomater 24 (2003) 1663. 
[10] J.M. González-Méijome, A. López-Alemany, J.B. Almeida, M.A. Parafita, M.F. Refojo, J Biomed Mater Res B 76 (2006) 412.

[11] J.M. González-Méijome, A. López-Alemany, J.B. Almeida, M.A. Parafita, J Biomed Mater Res B 88 (2009) 75.

[12] V. Guryca, R. Hobzova, M. Pradny, J. Sirc, J. Michalek, Contact Lens \& Anterior Eye 30 (2007) 215.

[13] M. Lira, L. Santos, J. Azeredo, E. Yebra-Pimentel, M.E.C.D. Real Oliveira, J Biomed Mater Res B 85 (2008) 361.

[14] M.J. Giraldez, C. Serra, M. Lira, M.E.C.D. Real Oliveira, E. Yebra-Pimentel, Opt Vision Sci 87 (2010) E475.

[15] B. Zhou, Y. Li, N.X. Randall, L. Li, J Mech Beh Biomed Mater 4 (2011) 1336.

[16] K.D. Jandt, Surface Science 491 (2001) 303.

[17] B. Bhushan, H. Fucks, M. Tomitori (Eds), Applied Scanning Probe Methods vol. VIII-X, Springer, Berlin-Heidelberg, 2008.

[18] B. Foster, American Laboratory, April (2012) 24.

[19] S.B. Kaemmer, Bruker Application Note 133 (2011), www.bruker.com.

[20] K. French, L. Jones, Optometry Today 48 (19) (2008) 38.

[21] E.P. Goldberg, S. Bhatia, J.B. Enns, The CLAO J 23 (1997) 243. 